\title{
TOWARDS INCLUSIVE TRAINING FOR INCLUSIVE EDUCATION (TEACHERS' VIEWS ABOUT EFFECTIVE PROFESSIONAL DEVELOPMENT FOR PROMOTING INCLUSIVE EDUCATION)
}

\author{
S. Rosmalily $\odot$, J. Woollard \\ University of Southampton (UNITED KINGDOM)
}

\begin{abstract}
Inclusive education is recognised by many countries. The practice, however, is inconsistent because of its complexity and variability of implementation. Because of the various contexts of Malaysia, with its diverse ethnicity, culture, religion, language, and socio-economic background, there are implications for the implementation and efficacy of initiatives to promote inclusive education. This study brings a better understanding of the successful promotion of inclusive education by focusing on Malaysian teachers' perspectives of inclusion, their practice and their professional development.
\end{abstract}

Effective continuing professional development (CPD) could enhance teacher competencies to respond to their diverse learners and those learners' needs. Responding to teachers' views of what works for them in their workplace, this research explores the effectiveness of CPD from the practitioners' perspectives. Using the rich and in-depth data gathered, a qualitative approach that employs descriptive and exploratory methods is used. Participants are purposely sampled from five national primary schools. 25 teachers, which include headteachers, are interviewed individually and 51 participated in eight focus group interviews. Theories of inclusive education and the 'Cognitive Activation in the Mathematics Classroom and Professional Competence of Teachers', (COACTIV) Model of Teachers' Professional Competence are adopted. The COACTIV model integrates theories of professionalism with the competency literature. According to the model, four aspects of competences need to be developed through professional development: beliefs, values, and goals; motivational orientations; professional knowledge; and self-regulation. These areas are explored through the thematic analysis using QSR NVivo software.

The findings are of value to those responsible for developing teacher training programme in Malaysia. At the school level, they will inform the probable topics and areas for school-based CPD programmes.

Keywords: Continuing professional development; inclusive education; inclusion.

\section{INTRODUCTION}

Through the 'Malaysia Education Blueprint 2013-2025', Malaysia highlights its commitment to inclusive education [1]. The targets include: ' $75 \%$ of students with special needs enrolled in inclusive programs by 2025 ' and 'every teacher equipped with basic knowledge of special education' [1, p. 4-17]. However, the various contexts of Malaysia as a multi-ethnic, multi-cultural, and multi-lingual country, as well as the educational system, policies, and laws bring challenges. To enable the transformation of the educational system, the school-based Continuous Professional Development (CPD) for in-service teachers is highlighted in developing high-quality teachers as part of the initiatives and strategies [1] towards its aspirations of an economically advanced inclusive society [2] in the $21^{\text {st }}$ century.

Therefore, this study investigates in-service teachers' CPD needs, gain insights to enhance support for teachers as they continue learning through their working lives, and brings a better understanding to the requirements for the successful promotion of inclusive primary education in Malaysia. Concurrently, teachers' views about inclusive education and helpful school-based CPD to promote inclusive education are obtained to better understand their perceptions.

\section{INCLUSIVE EDUCATION}

Malaysia struggles to provide access to education for children with disabilities and inclusive education [3]. Introduced in the Education Act 1996, it is the extension of education provision for SEN pupils in the mainstream, apart from the provision of special education [4]. The notion of inclusive education focuses on SEN, where inclusion is consistent with the 1980s' integration model [4], rather than the 'total inclusion' without condition [5]. Furthermore, the various contexts of Malaysia as a multi-ethnic, multi- 
cultural, and multi-lingual country with different schooling options influence the successful promotion of a universal inclusive education. Studies conducted at practitioner level have argued for change $[4,6]$. Compounding this, it has been demonstrated that teachers are lacking the knowledge and understanding of the values of inclusive education, which necessitate CPD $[4,7,8]$.

\subsection{Conceptualising inclusive education}

\subsubsection{The development of inclusive education}

Literature reviews highlight the significance of the historical context [9-12] to its theoretical and empirical transformation [13] (See Fig 1). Closely related to the field of special education and disability, the continuous debate resulted in the evolution of the concept of inclusion [14]. Consequently, from the emphasis on SEN and focusing on deficits, inclusion, means all pupils must be supported and facilitated to prosper [15].

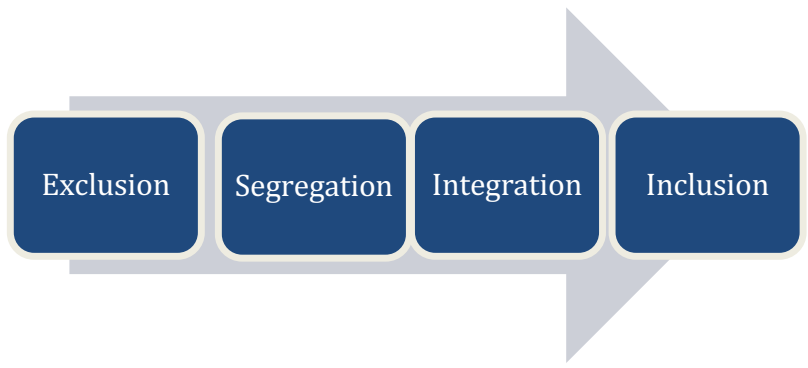

Figure 1. The development of inclusive education

From this wider perspective, transforming the educational system [16], and emphasizing on inclusive practice $[15,17]$ are seen as a vital process for inclusive education. With this, inclusion involves educational equity and equality [16], for all pupils irrespective of differences. Recently, the Incheon Declaration for 'Education 2030: Towards inclusive and equitable quality' reaffirms the commitment to make the necessary changes in worldwide policies [18]. Certainly, the process is arduous [16], requiring inclusive values in policy formulation [18, 19]; changing ways of thinking [20], roles of organizational cultures and leadership [21, 22]; implementing practices at all levels [23]; and accepting the core pedagogical principles of transformability to enhance pupil learning capacity of the co-agency and everybody [24, 25]. Significantly, teacher preparation and education are crucial since their understanding, ethos and expertise influence on how they meet a wider variety of pupils. By empowering teachers, they in turn could empower learners.

\section{TEACHER CONTINUOUS PROFESSIONAL DEVELOPMENT}

Professionally qualified and quality teachers are vital for any educational reformation [26]. Teachers are viewed as 'change agents' [27], therefore must be prepared with multiple roles to respond to increasing diversity in classrooms [28] beyond their initial training. Within this context of the study, all related terms, such as lifelong learning [29], are referred as CPD. We choose the term 'professional development' not 'professional learning' because the former term is used in the Blueprint and understood by most Malaysian teachers.

\subsection{The $21^{\text {st }}$ century of challenge}

As the world enters the $21^{\text {st }}$ century of with its increasingly diversified, globalized and interactive nature, with emerging technologies impacting on all aspects of life, providing quality education and preparing pupils are complex issues. Moreover, the challenges posed by the changing nature of the contemporary knowledge society, pupils' needs, policy and pressures to the existing association between professionalism and autonomy lead to considerations of initial teaching capabilities, and the relevance and appropriateness of teachers' long-held pedagogical and knowledge repertoires [30]. Therefore, teachers as professionals must evolve [31]. Increasing the provision of effective CPD and support is fundamental in developing quality teachers. 


\subsection{Effective CPD}

Research shows various perspectives when conceptualising CPD. For teachers to become effective, CPD programmes should evidence a positive impact on teaching practice, and make a significant difference to pupils' academic, social and behavioural progress [32]. Such CPD is perceived to support teachers in contributing to and shaping education policy and practice, associates itself with the transformative model [33]. The concrete and classroom-based CPD [34] enables educators to develop the knowledge and skills needed to address pupils' learning challenges [35]. From this perspective, teachers are responsible for their self-efficacy and engaging in self-directed learning via constant reflective activities [36]. Teachers must become 'active agents of their own professional growth' [37, p. 73]. The growing importance of voluntary learning and development is implied by the requirement for effective participation in contemporary, technology and knowledge-based economy and society [29].

To support teachers to teach creatively and confidently, activities should be planned appropriately once needs have been identified [38]. Teachers too face constant challenges by being responsible for other tasks and priorities within and outside of schools. Therefore, obtaining teacher views is significant as they are the ones who know their pupils best and understand the challenges and reality of day-to-day experiences within school contexts. Teachers involvement in selecting their own CPD activities leads to greater improvements that are demonstrated in subject knowledge, and their commitment to teaching, teaching practice and the learning of their pupils [39].

\section{METHODOLOGY}

This research employs interpretive qualitative research design with multiple methods. Research methods include semi-structured individual interviews of 60 minutes duration following classroom observations of the same teacher. Interviews can be flexible and effective when seeking detailed answers to research questions [40]. There are also focus group interviews of 90 minutes each with five to seven participants per group. The overt non-participant semi-structured classroom observations help to understand the context and inform some of the questions for the individual interviews. The analysis of the individual interviews and focus group interviews is integrated to serve the dual purpose of exploring the phenomenon of interest and completing or confirming the data of group perspectives and individual views [41]. Avoiding the language barriers, interviews are in Malay language (the national language) and recorded with the participants' consent.

\subsection{Data collection}

A purposive sampling [42] strategy is adopted. Based on one-shot basis, data were collected from five national primary schools in Kinta District, Perak: three schools with the Special Education Integration Program (SEIP) for learning difficulties and two non-SEIP schools. Participants include the head teachers, senior assistants, mainstream and special education teachers (at SEIP schools only) involved in the study. Table 1. shows the participant distribution.

Table 1. Data collection

\begin{tabular}{|c|c|c|c|}
\hline \multicolumn{2}{|c|}{ School } & \multicolumn{2}{c|}{ Number of Participants } \\
\hline SEIP & Non-SEIP & Individual interviews & Focus group interviews \\
\hline 1 & & 11 & 13 (2 groups) \\
\hline 2 & & 0 & 7 (1 group) \\
\hline 3 & & 2 & 5 (1 group) \\
\hline & 4 & 7 & 13 (2 groups) \\
\hline & 5 & 6 & 13 (2 groups) \\
\hline
\end{tabular}




\subsection{Data Analysis}

Data are thematically analyzed via inductive approach using the Computer Assisted Qualitative Data Analysis (CAQDAS) NVivo 11 through the lens of interpretivist and constructivist approaches [43]. The eclectic coding involves a constant splitting and lumping process of the coded text to re-assess and crystallize the codes, categories and themes [44]. The approach is 'Cognitive Activation in the Mathematics Classroom and Professional Competence of Teachers' (COACTIV) Model of Teacher Professional Competence [45]. The model integrates theories of professionalism with the competency literature. According to the model, four aspects of competences need to be developed through professional development: beliefs, values, and goals; motivational orientations; professional knowledge; and self-regulation. The data analysis was carried out in the Malay language by a native Malay speaker. Only the themes, nodes and excerpts are translated to English.

\section{FINDINGS AND DISCUSSION}

The excerpts presented are the translated version, without changes in the meaning and nuance of the original. Participants' perspectives about their requirements for helpful and effective CPD are influenced by their understanding of the Malaysia practice. That practice is based on a narrow concept of inclusive education. The illustrated excerpts are cited from individual interviews and focus groups ' $a$ ' and ' $b$ ' in which different participants are acknowledged by numbers.

\subsection{Influencing factors}

The research shows a mixed response to school-based CPD. The positive responses are highlighted as being the basis to enhance knowledge and skills. The negative responses arise from the means of implementation and the reality of practice in schools. For example,

"School-based CPDs are always about the same thing. Motivation to teach, teaching methods, techniques. Teachers, of 20-30 years, felt nothing changes. Keep repeated to remind us."

The excerpt above illustrates several issues including the topic, activities, and more importantly that the participant thinks that experienced teachers feel stagnant. It also implies the need for the teacher to reflect on their own engagement in CPD activities.

\subsubsection{Direct factors}

The direct factors namely: topic, content, and objective; activities and implementation; and target group. From this perspective, all participants emphasize the relevancy of such activities to teachers of different specialisation and the subjects they teach. Some mainstream participants also report the need to understand inclusive education, special education and SEN for successful promotion of inclusive education, but others totally disagree. The disagreement is based on their beliefs and values that SEN pupils would be unable to cope with the mainstream curriculum and that it is better for them to learn with the special education teachers. However, this view, based on medical model [46] of SEN pupils do not include the physically disabled pupils of whom are stressed for improved facilities. Concurrently, the special education teachers believe they need more sessions about special education to be more effective. To evidence:

"There're pros and cons. Sometimes, the school-based CPD pressures us. Whereas outside courses associate better with our option-subjects we teach. Teachers must know and mindful of everything - other subjects, disciplines. It's too much."

In other examples:

"Like... about preparing teaching aids, it helps. (Teacher 1)

Yes. Related to us, like a session about Autism, followed by a workshop. That's ok (Teacher 2).

We could use... beneficial. Thus, effective. But, if [it's nonsense], it wouldn't affect our teaching practices, the teaching and learning activities (Teacher 1).

[Nothing suitable]. We couldn't practice- apply them in the classroom (Teacher 3). 
Whatever it is, school-based CPD must relates to our core business (Teacher 1).

Must be focused (Teacher 4).

Focused activities such as how to tackle pupils (Teacher 1).

Professional development (Teacher 2).

Agree. And, we would follow the current $21^{\text {st }}$ teaching and learning practice... Definitely effective (Teacher 1)."

In the above excerpts, the relevancy of the CPD to current teaching practices is emphasised; participants also voice concern about the practicality of the learning sessions. Such sessions provide hands on activities that enable them to teach in the real classrooms with diverse pupils. It is believed that these sessions of school-based CPD are effective and allow teachers to develop professionally. This relates to the aspects of professional knowledge, values, and motivation to learn and develop as suggested in the COACTIV model [45]. Noteworthy, participants 1 and 2 are special education teachers and participants 3 and 4 are mainstream teachers. Participants highlight the $21^{\text {st }}$ century teaching and learning practices as promoted by the government that emphasise the use of ICT skills [1].

Additionally, with regards to the implementation and activities of school-based CPD, all participants express the need for engaging, interesting, and collaborative aspects. Some comments from the focus groups:

"Must be interesting with suitable time and place.

But then the administrator reasons out as of no time and cost."

Similarly, many participants point to the Saturday activities which they consider not convenient for many teachers. Moreover, it is implied that the ministry is not aware of this issue. To evidence:

"We limit the school-based CPD activities. No need to do that on Saturday. Use the free time on weekdays. But that's not happened. The MOE wouldn't know about this."

Most participants expressed their frustration about the absence of their voice in the implementation of school-based CPD and the school-based CPD activities.

"School-based CPD is not what we require.

Everything is from the higher-ups."

Related to teacher learning in the $21^{\text {st }}$ century, the online CPD offers flexibility [1], just enough, and just in time, which fit teachers' busy life schedule may provide the solution. However, the focus group participants believe that the online CPD is disconnected and irrelevant to the real problems in classrooms, although, they thought, perhaps well intentioned.

"Online courses- nothing beneficial.

Like the obligatory BOSOT, more to country development. And, it's online- theory.

Online courses are more towards enhancing ICT skills. Nothing related."

In this example, the content and purpose of the courses are queried whereby the online courses are perceived as focusing on ICT literacy. Some participants believe that the ICT skills of young teachers are sufficient of which such CPD is useless to them, and they rather need more supporting materials, in contrast, others believe they need to acquire the skills to facilitate them in classrooms. Thus, illustrated:

"[We need] ICT skills. Apart from the ICT materials and tools, we have to master the skills. To explain to pupils and assist us in teaching and learning activities."

\subsubsection{Indirect factors}

The indirect factors mostly involve the education system, support, and workplace dynamic. For these reasons, the expressions were mostly about the issues and challenges as the result of the educational system, the segregated provision for SEN pupils, and issues of whereby some feel that they do not gain anything from the sessions. Therefore, the government is urged to put more effort in studying the reality at schools and making the CPD relevant. For example,

"Must meet certain needs such as materials, location, facilities, access, etcetera. For example, not all schools have the access to data, internet access... to ensure that the information reach all 
teachers... Also, the alliance between teachers and staffs to ensure that programs have higher successful rate to achieve the goal."

The support includes the facilities and the follow-up. A participant referring to 'iThink' (the concept map as one way of learning) implied that the hands-on activities and collaborative sessions increased the teacher's confidence in their teaching practice:

"We couldn't just take what we learn from school-based CPD direct into our teaching and learning activities. We are required to complete the module online.... Still, we are not sure how to use them in classrooms. So, we do school-based CPD based on the subject, discuss in groups, and draw out the iThink map for particular topics. It helps us to guide the pupils. We're confident. Because to teach, we have to know more. Previously, with theory, now with practice."

This example shows another issue:

"Teachers want courses to inspire them to teach, feel appreciated... But now, courses (schoolbased) are just... finally, teachers must do everything. We feel discouraged... Perhaps, because of the economy. Yet, everything requires result... the tip-top. But, no investment, no support, so we're... And, high teachers' workload. If the husband works in the same line, he would understand. Still, the public say many things, "teachers work half day, it's school holiday, then teachers too..."

It is also vital to have positive working environments, and relationships to allow collaboration and team learning for transformative change. In this example, evidently self-inquiry and self-regulation of teachers are crucial for them to be more competence- that correspond to the adapted Model [45].

"Previously, the work culture was different among the senior teachers. We tend to follow, learn from them. But these newcomers aren't. I'm not sure. Perhaps too much workload, anxious for unable to handle tasks... New teachers, nowadays, don't want to learn, or don't care. So, the workload isn't balanced."

Participants perceive that school-based CPD is ineffectively implemented with the 'one-size-fits-all' [34], of which they do not consider the varying levels of motivation, interest, knowledge and skills of teachers. In other words, the teachers' voice. Overall, the findings match with expectations arising from the literature review. For example: contextual-based [34]; engaging; applicable and beneficial [38]; whereby the intrinsic and extrinsic influencing factors as adult learners are considered [36]; collaborative; learning by doing; [32] and self-direct [36]. Obtaining teachers' views is important to their professional development [47] that evidence greater improvements in subject knowledge, and their commitment to teaching, teaching practice and the learning of their pupils [39, 48].

The findings also demonstrate that teachers lack awareness of the potential of online CPD for their development. Lieberman and Pointer-Mace [49] suggest teachers make use of the media tools and social network resources as means of professional development. Reviewing the findings, teachers' views are understandable because, although their own time is mostly flexible, there are limitations [35]. In this case the limitations include, the provision of useful learning content, interactive discussions, and teacher ICT skills as well as the availability of internet access. Therefore, it is important to ensure that the traditional and online CPD provide evidence of relevancy in improving teacher knowledge and skills, thus, practice, and consequently all pupils' achievement.

\section{CONCLUSIONS AND RECOMMENDATIONS}

To conclude, in embracing the concept of inclusive education, CPD activities relating to teaching practice and considering teachers as adult learners is vital. Teachers are professionals that are responsible in shaping the world [23]. However, they too may struggle with other challenges. In this sense, listening to their voice is fundamentally a major step in supporting and facilitating them to enhance their competencies and become more effective to all pupils. The bottom up approach and transformative leadership are preferred, whereby teachers have the opportunities to suggest and receive feedback about their requirements from school-based CPD and practices. Secondly, the concept of CPD too, must be inclusive - involving elements of flexibility that embrace strategies in supporting different teachers, ensuring that they are relevant to improving teaching practice. Whilst some may prefer the face-to-face CPD, others may prefer the online CPD that is accessible anytime and anywhere. For both, engaging activities where teachers could apply the theory, and practise the knowledge learned as well as giving the support, thus inspire them to experiment and master the skills, are favoured by all teachers. Therefore, it seems that the blended approach which is more flexible within the school context may be 
the solution. Nonetheless, even to realise this approach, basic features of ICT skills and facilities need to be improved.

In the fore is the understanding and core values of the concept of inclusive education by all teachers (irrespective of attributes and roles). Good practice also entails a clear understanding of the teachers' roles and competencies in both the mainstream and special education. There is a responsibility and accountability for teachers to engage in self-reflective activities and self-directed learning for professional growth. With positive values, and mutual respect, then the professional community of the school, could learn and work together as a joint enterprise to enhance their inclusive practice. This has implications for the provision of inclusive and effective CPD.

\section{ACKNOWLEDGEMENTS}

The authors wish to thank the Malaysian Ministry of Education for the financial support and the University of Southampton for facilitating the research.

\section{REFERENCES}

[1] Ministry of Education Malaysia (MOE), "Malaysian Education Blueprint 2013-2025 (Preschool to Post-Secondary Education)", MOE, 2013.

[2] Economic Planning Unit (EPU), Prime Minister's Department Malaysia, "Eleventh Malaysia Plan 2016-2020: Anchoring Growth on People", EPU, 2015.

[3] L. W. Lee, and H. M. Low, "The Evolution of Special Education in Malaysia", British Journal of Special Education, vol. 41, no. 1, pp. 42-58, 2014.

[4] Z. M. Jelas, and M. Mohd Ali, "Inclusive education in Malaysia: Policy and practice", International Journal of Inclusive Education, vol. 18, no. 10, pp. 991-1003, 2014.

[5] Ministry of Education Malaysia (MOE), "Development of education: The national report of Malaysia", MOE, 2004.

[6] S. Hussin, Quek, A.H. and Loh, S.C., "Policy into practice: the challenge for special education in Malaysia", in 11th International Conference on Experiential Learning, Sydney, Australia, 2008.

[7] A. H. Adnan, and I. A. Hafiz, "A Disabling Education: the case of disabled learners in Malaysia", Disability \& Society, vol. 16, no. 5, pp. 655-669, 2001.

[8] L. W. Lee, and H. M. Low, "'Unconscious' inclusion of students with learning disabilities in a Malaysian mainstream primary school: Teachers' perspectives", Journal of Research in Special Educational Needs, vol. 13, no. 3, pp. 218-228, 2013.

[9] D. Armstrong, A. C. Armstrong, and I. Spandagou, "Inclusion: by choice or by chance?", International Journal of Inclusive Education, vol. 15, no. 1, pp. 29-39, 2011.

[10] S. Gibson, "When rights are not enough: What is? Moving towards new pedagogy for inclusive education within UK universities", International Journal of Inclusive Education, vol. 19, no. 8, pp. 875-886, 2015.

[11] P. Clough, and J. Corbett, Theories of inclusive education: a student's guide, London: Sage, 2000.

[12] M. Doveston, "Review of Inclusive education: readings and reflections", European Journal of Special Needs Education, vol. 20, no. 2, pp. 244-246, 2005.

[13] R. Opertti, Z. Walker, and Y. Zhang, "Inclusive education: From targeting groups and schools to achieving quality education as the core of EFA", The SAGE Handbook of Special Education: Two Volume Set, L. Florian, ed., pp. 149-170, London: SAGE Publications Inc., 2014.

[14] R. Opertti, J. Brady, and L. Duncombe, "Moving forward: Inclusive education as the core of education for all", Prospects, vol. 39, no. 3, pp. 205-214, 2009.

[15] P. Farrell, "The impact of research on developments in inclusive education", International Journal of inclusive education, vol. 4, no. 2, pp. 153-162, 2000. 
[16] J. Allan, "Reflection: Inconclusive education? Towards settled uncertainty", Theories of Inclusive Education, P. Clough and J. Corbett, ed., pp. 43-46, London: Paul Chapman, 2000.

[17] M. Ainscow, From special education to effective schools for all: a review of progress so far, in L.Florian (Ed). The SAGE handbook for Special Education, London: SAGE, 2007.

[18] UNESCO, Incheon Declaration Education 2030, UNESCO, Republic of Korea, 2015.

[19] T. Booth, and M. Ainscow, Index for inclusion: developing learning and participation in schools, Bristol: Centre for Studies on Inclusive Education (CSIE), 2002.

[20] M. Ainscow, "Developing inclusive education systems: what are the levers for change?", Journal of educational change, vol. 6, no. 2, pp. 109-124, 2005.

[21] M. Ainscow, and A. Sandill, "Developing inclusive education systems: the role of organisational cultures and leadership", International Journal of Inclusive Education, vol. 14, no. 4, pp. 401-416, 2010.

[22] T. Booth, and M. Ainscow, Index for inclusion: developing learning and participation in schools, Third ed., Bristol, UK: Centre for Studies on Inclusive Education (CSIE), 2011.

[23] R. Slee, The irregular school: Exclusion, schooling and inclusive education: Taylor and Francis, 2011.

[24] S. Hart, "Learning without limits", Inclusive Education: Learners and Learning Contexts, M. Nind, K. Sheehy and K. Simmons, eds., pp. 219-232, London: David Fulton publishers, 2003.

[25] S. Hart, and M. J. Drummond, Learning without limits: Constructing a pedagogy free from determinist beliefs about ability: SAGE Publications Inc., 2014.

[26] UNESCO, "2015 NGO Forum Declaration: Towards the Right to Inclusive Quality Public Education and Lifelong Learning beyond 2015", in World Education Forum, Incheon, Republic of Korea, 2015.

[27] C. Day, P. Sammons, and G. Stobart, Teachers matter: Connecting work, lives and effectiveness: McGraw-Hill Education (UK), 2007.

[28] K. Allan, "Personal and Professional Development: Becoming an Inclusive Practitioner", The STeP Journal, vol. 2, no. 3, pp. 59-69, 2015.

[29] K. Collin, B. Van der Heijden, and P. Lewis, "Continuing professional development", International journal of training and development, vol. 16, no. 3, pp. 155-163, 2012.

[30] L. Darling-Hammond, and J. Bransford, Preparing teachers for a changing world: What teachers should learn and be able to do: John Wiley \& Sons, 2007.

[31] L. Evans, "Professionalism, professionality and the development of education professionals", British journal of educational studies, vol. 56, no. 1, pp. 20-38, 2008.

[32] C. Walter, and J. Briggs, What professional development makes the most difference to teachers?, Report, vol. 20, University of Oxford, Oxford, 2012.

[33] A. Kennedy, "Models of Continuing Professional Development: A Framework for Analysis", Professional Development in Education, vol. 40, no. 3, pp. 336-351, 2014.

[34] M. Barber, and M. Mourshed, How the world's best-performing schools systems come out on top: McKinsey \& Company, 2007.

[35] H. Mizell, Why professional development matters, Learning Forward, Oxford, 2010.

[36] D. Muijs, L. Kyriakides, G. van der Werf, B. Creemers, H. Timperley, and L. Earl, "State of the art - teacher effectiveness and professional learning", School Effectiveness and School Improvement, vol. 25, no. 2, pp. 231-256, 2014.

[37] A. Schleicher, Preparing Teachers and Developing School Leaders for the 21st Century: Lessons from around the World: OECD Publishing, 2012.

[38] J. Anderson, "The content and design of in-service teacher education and development", in National Teacher Education Policy Conference, Midrand, 2001, pp. 21. 
[39] P. Cordingley, M. Bell, S. Thomason, and A. Firth, The impact of collaborative continuing professional development (CPD) on classroom teaching and learning in, Research Evidence in Education Library, EPPI-Centre, Social Science Research Unit, Institute of Education, London, 2005.

[40] J. W. Creswell, Research Design: Qualitative, Quantitative, and Mixed Methods Approaches (International Student Edition), 4th ed., Los Angeles: Sage, 2014.

[41] S. D. Lambert, and C. G. Loiselle, "Combining individual interviews and focus groups to enhance data richness", Journal of advanced nursing, vol. 62, no. 2, pp. 228-237, 2008.

[42] L. Cohen, L. Manion, and K. Morrison, Research Methods in Education, 7th ed., New York: Routledge, 2011.

[43] J. Saldaña, The Coding Manual for Qualitative Researchers 3rd ed, Los Angeles: SAGE, 2015.

[44] P. Bazeley, Qualitative data analysis: Practical strategies: Sage, 2013.

[45] J. Baumert, and M. Kunter, "The COACTIV model of teachers' professional competence", Cognitive Activation in the Mathematics Classroom and Pofessional Competence of Teachers, M. Kunter, J. Baumert, U. Klusmann, S. Krauss and M. Neubrand, eds., pp. 25-48, New York: Springer, 2013.

[46] G. Fulcher, Disabling policies? A comparative approach to education policy and disability, London: Falmer, 1989.

[47] T. R. Guskey, Evaluating Professional Development, Thousands Oak, CA: Corwin Press, 2000.

[48] R. C. Moore, Constructing a narrative of teacher development: Piecing together teacher stories, teacher lives, and teacher education, New Orleans, LA: University of New Orleans, 1995.

[49] A. Lieberman, and D. Pointer-Mace, "Making practice public: Teacher learning in the 21st century", Journal of Teacher Education, 2009. 